\title{
Doença pulmonar intersticial como primeirla manifestação de síndrome anti-sintetase
}

\author{
Interstitial lung disease as the first manifestation \\ of anti-synthetase syndrome
}

\author{
Mário Pires ${ }^{1}$, Magda Sousa ${ }^{1}$, Ana Montez ${ }^{1}$, Ana Araújo ${ }^{1}$ \\ ${ }^{1}$ Serviço de Medicina Interna, Centro Hospitalar do Baixo Vouga - Aveiro. Portugal.
}

\begin{abstract}
Resumo
Considera-se a presença do síndrome em pacientes com anticorpos antisintetase associados a duas das seguintes características, doença pulmonar intersticial, miopatia inflamatória e poliarterite inflamatória.

Apresentamos o caso de um homem com diagnóstico efectuado há 13 anos, durante um internamento por "pneumonia", apresentando queixas de dispneia para esforços e cansaço fácil com 3 meses de evolução. Durante 0 internamento é identificada uma doença pulmonar intersticial e posteriormente surge um quadro de mialgias com elevação marcada das enzimas musculares. A electromiografia mostrou um padrão sugestivo de miopatia e identificou-se anticorpos anti-Jo-1, estabelecendo-se 0 diagnóstico de síndrome anti-sintetase. Sob terapêutica imunossupressora desde então, mantém seguimento em consulta externa, encontrando-se clinicamente bem.
\end{abstract}

Palavras chave: síndrome antisintetasa; enfermedad pulmonar intersticial; miositis; anti-Jo-1.

\section{Introdução}

0 síndrome anti-sintetase caracteriza-se pela associação de duas das seguintes características, doença pulmonar intersticial (DPI), miopatia inflamatória e poliarterite inflamatória com a presença de anticorpos anti-sintetase. Laboratorialmente é marcada pela presença de anticorpos anti-aminoacil-RNAt sintetase (anti-sintetase), sendo mais frequente 0 anti-Jo- ${ }^{1}$. Trata-se de uma doença pouco comum, com uma prevalência de 1,5 por 100.000 habitantes $^{2}$, tendo sido descrita em 1990 por Marguerie $\mathrm{C}$, et al. ${ }^{3}$

Apesar de se tratar de uma doença sistémica, pode manifestar-se inicialmente apenas com envolvimento pulmonar e este pode dominar o quadro clinic $0^{4}$. A principal causa de morbimortalidade é a evolução da doença pulmonar ${ }^{5,6}$.

\section{Caso Clínico}

Apresentamos o caso de um homem, de 65 anos, não fumador, com antecedentes de hiperplasia benigna da próstata e doença coronária, que apresentava queixas de dor pré-cordial, cansaço fácil e dispneia para pequenos esforços com 3 meses de evolução associado nas duas ultiamas semanas a sudorese nocturna e tosse produtiva. Recorreu à consulta de Cardiologia (em Junho de 2000) tendo realizado prova de esforço e ecocardiograma que não mostraram alterações. Posteriormente recorreu ao Serviço de Urgência (SU), onde no estudo realizado se constatou a presença no RX de tórax

\begin{abstract}
The syndrome is generally considered present in patients with an antisynthetase antibody plus two of the following features, interstitial lung disease, inflammatory myopathy, and inflammatory polyarthritis.

We report the case of a man with diagnosis made 13 years ago, during hospitalization for "pneumonia" with complaints of effort dyspnea and tiredness with 3 months of evolution. Non infectious interstititial lung disease was finally demonstrated and subsequently myalgia occurs with a marked elevation of muscle enzymes. Electromyography shows a pattern suggestive of myopathy and with identification of anti-Jo-1 the diagnosis of anti-synthetase syndrome is established. The patient is on immunosuppressive treatment since then, being followed at the outpatient clinic, without symptoms at the present moment.
\end{abstract}

Keywords: anti-synthetase syndrome; interstitial lung disease; anti-Jo-1; myositis.

de opacidades heterogéneas de ambas as bases e hipoxémia $\mathrm{pO}_{2}$ de $69,1 \mathrm{mmHg}$ ) na gasimetria arterial. Este quadro foi interpretado como pneumonia adquirida na comunidade e foi iniciada terapêutica com amoxicilina + ácido clavulâmico. Houve melhoria da tosse, febre e a expectoração, mas manteve as restantes queixas. Pondo-se em causa o diagnóstico inicial de pneumonia da comunidade, foi realizada pesquisa de BK, que foi negativa, e TC-torácica que mostrou no lobo médio direito e em ambos os lobos inferiores áreas irregulares em vidro despolido, densificação intersticial e alterações fibróides de aspecto organizado em favo (imagem 1).

Na sequência realizou-se broncofibroscopia com lavado broncoalveolar que apenas mostrou sinais inflamatórios com hiperemia da mucosa, e no lavado células epiteliais descamadas com alguns linfócitos e polimorfonucleares neutrófilos. Foram realizados outros exames complementares de diagnóstico realizados, nomeadamente ecografia abdominal, cultura de expectoração e proteinograma electroforético, cujos resultado foram normais.

Perante este quadro de doença pulmonar intersticial iniciou-se prednisolona $60 \mathrm{mg}$ por dia, com melhoria clínica. Na história clínica não foram identificados factores sugestivos da etiologia das alterações pulmonares, nomeadamente exposição ocupacional.

Duas semanas após a alta, mantendo corticoterapia (prednisolona $60 \mathrm{mg} / \mathrm{dia}$ ) o quadro clínico agrava-se. Surgem mialgias dos membros, rigidez das cinturas pélvica e escapular (principalmente matinal) e novamente cansaço fácil com dispneia. Ao exame objectivo constatou-se défice de força muscular e rigidez das cinturas. 
Imagem 1. TC Torácica realizada em 2000 (a) e em 2008 (b).

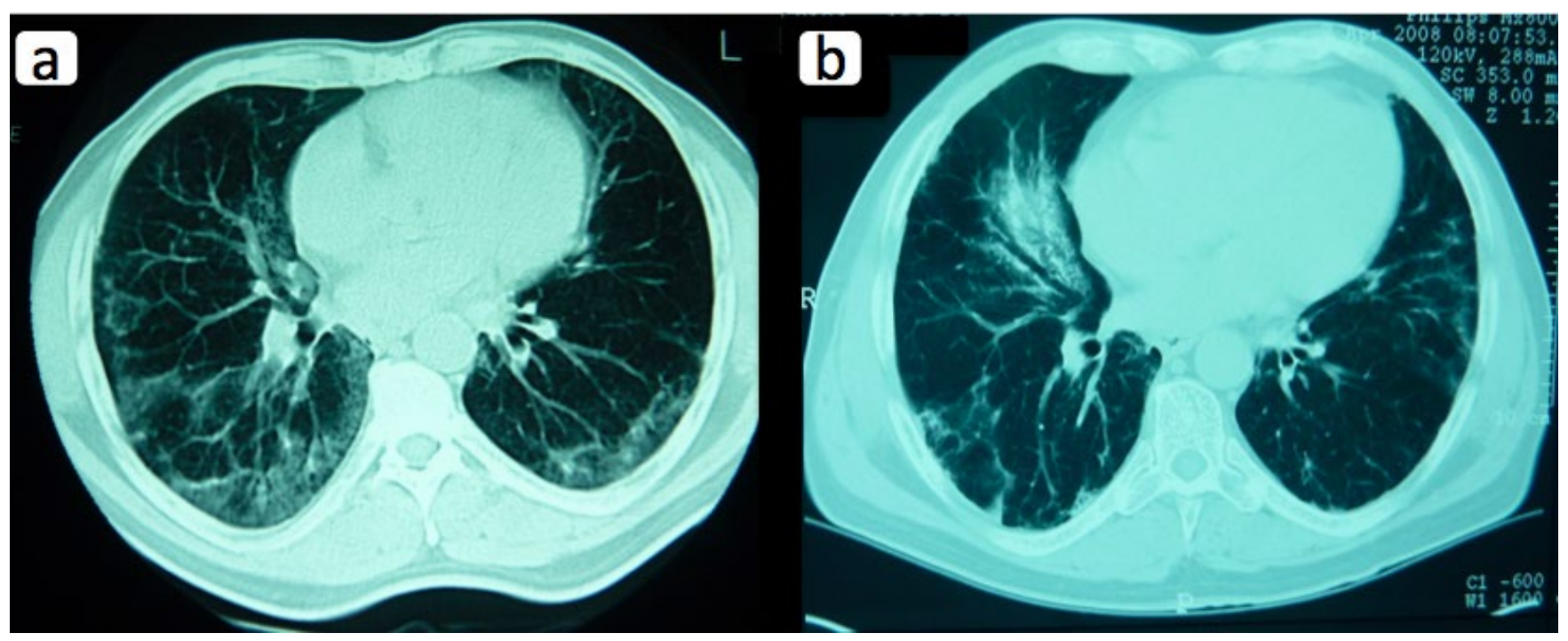

Não apresentava alterações cutâneas, das mãos (nomeadamente fenómeno de Raynaud, fissuras ou hiperqueratose), sinais de artrite ou artralgias. No estudo analítico de salientar a elevação da CPK e a presença de auto-anticorpos (ANA e anticorpo anti-Jo-1). Foram realizadas electromiografia, cujo resultado sugeriu um processo inflamatório, e biópsia muscular que não demonstrou alterações.

Perante a presença de doença pulmonar intersticial associada a miosite (biópsia sem alterações, mas clínica compatível e CPK elevada) com anticorpos anti-aminoacil-RNAt sintetase, neste caso anti-Jo-1, estabeleceu-se o diagnóstico de síndrome anti-sintetase ${ }^{1}$. Iniciou-se azatioprina na dose de 50mg id e a dose de prednisolona foi aumentada para 75mg. Com o início da imunossupresão houve melhoria clínica significativa. Na continuação do estudo, em 2001, efectou-se estudo funcional respiratório que mostrou capacidade pulmonar total ligeiramente diminuída, sem outras alterações.

Em 2008 repetiu TC-torácico (imagem 1) cujo resultado mostrou agravamento das alterações fibroticas, "(...) acentuadas alterações da organização estrutural atingindo sobretudo os andares inferiores (...) espessamento intersticial intra-lobular e septal intra-lobular. (...) Estes achados traduzem já alterações de fibrose." No entanto o paciente não voltou a desenvolver sintomatologia respiratória.

Ao longo dos anos, a terapêutica imunossupressora foi sendo ajustada de acordo com as queixas do doente (principalmente mialgias e cansaço, sem queixas de dispneia). Numa tentativa de melhor controlo da doença houve um período de 6 meses em que a azatioprina foi substituída por metotrexato mas sem melhoria clínica, pelo que foi retomada a Azatioprina associada a corticóide. Desde há 5 anos que a terapêutica está estabilizada nos 100mg de azatioprina e 15mg de prednisolona. Em 2012 realizou novo ecocardiograma que não mostrou sinais de hipertensão pulmonar (PSAP de 34mmHg). Clinicamente não tem apresentado queixas musculares ou respiratórias e a CPK tem-se mantido em valores aceitáveis (Imagem 2).

Imagem 2. Evolução dos valores de CPK ao longo dos anos, correlacionado com a terapêutica imunossupressora.

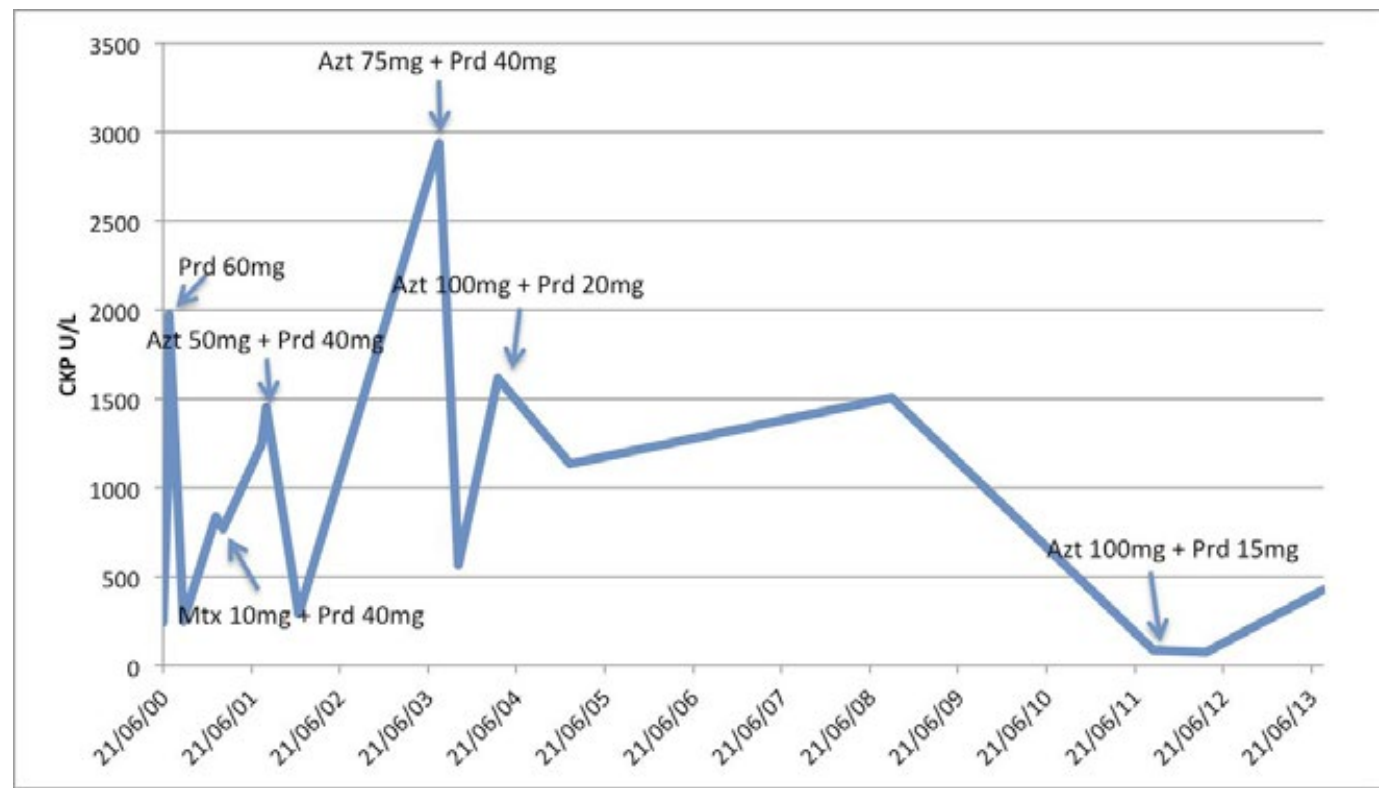


Tabela 1. Parâmetros analíticos

\begin{tabular}{|l|c|c|}
\hline & $\begin{array}{c}1^{0} \text { Internamento } \\
21 / 06\end{array}$ & $\begin{array}{c}\text { Reinternamento } \\
27 / 07\end{array}$ \\
\hline Hemoglobina (g/dl) & 14.7 & 13.8 \\
Leucócitos (x109/L) & 12,00 & 11,70 \\
Neutrófilos (\%) & $72 \%$ & $69 \%$ \\
Linfócitos (\%) & $19.7 \%$ & $22.2 \%$ \\
Plaquetas (x109/L) & 211 & 239 \\
VS (mm) & 38 & 35 \\
PCR (mg/dl) & 1.6 & 1.4 \\
LDH (U/L) & 273 & 472 \\
CK (U/L & 242 & 1972 \\
Mioglobina (ng/ml) & 103 & 360 \\
ANA & - & $<1 / 40$ \\
Anti-dsDNA & - & negativo \\
anti-RNP & - & negativo \\
anti-Sm & - & negativo \\
anti-Sm & - & positivo \\
\hline
\end{tabular}

\section{Discussão}

Os elementos principais para o diagnóstico do síndrome anti-sintetase são a presença de um anticorpo anti-aminoacil-RNAt sintetase, acompanhado de miosite, doença pulmonar intersticial ou ambas ${ }^{7}$. Podem existir também artrite e fenómeno de Raynaud. Estão descritos 6 anticorpos anti-sintetase: Jo 1, PL 7, PL 12, EJ, OJ e KS, sendo 0 anti-Jo 10 mais frequente ${ }^{8}$.

Em mais de 60\% dos casos de síndrome anti-sintetase, ocorre atingimento pulmonar ${ }^{3}$, mas esta não é a forma inicial de apresentação mais frequente. Em $50 \%$ dos doentes a miosite e a DPI surgem simultaneamente, enquanto que em $37 \%$ a DPI é a manifestação inicial9,4. A instalação da dispneia nos doentes com DPI pode ocorrer gradualmente (ao longo de meses, como no caso aqui apresentado), mas em alguns doentes a intalação pode ser aguda ou subaguda (dias ou semanas) $)^{10}$.

A terapêutica habitual consiste no uso de corticosteróides em combinação com um agente imunossupressor (azatioprina, ciclofosfamida ou metotrexato) ${ }^{11}$. Em casos resistentes à terapêutica convencional tem sido usado rituximab com algum sucesso ${ }^{12}$. É mais frequente haver uma boa resposta à terapêutica a nível muscular, mas apesar do tratamento imunossupressor pode continuar a haver detioração pulmonar, sendo esta a principal causa de morbimortalidade ${ }^{6}$. A hipertensão pulmonar tem uma prevalência significativa nos doentes com DPI e acarreta um aumento significativo da mortalidade. Nestes casos a estratégia terapêutica pode passar pelo transplante pulmonar. ${ }^{13}$

Neste caso em particular as queixas iniciais foram pulmonares seguidas pouco depois por sintomas musculares. Com a terapêutica os sintomas respiratórios foram mais facilmente controlados do que os musculares. Apesar de imagiologicamente existir agravamento e embora não exita novo estudo funcional respiratório, ao longo destes 13 anos não houve detioração da clínica respiratória, nem sinais de hipertensão pulmonar, o que torna o prognóstico mais favorável.

\section{Referencias}

1. Love LA, Leff RL, Fraser DD et al. A new approach to the classification of idiopathic inflammatory myopathy: myositis-specific autoantibodies define useful homogenous patients groups. Medicine 1991;70:360-374.

2. Imbert-Masseau A, Hamidou M, Agard C, Grolleau JY, Chérin P. Antisynthetase Syndrome. Joint Bone Spine. 2003;70(3):161-8.

3. Marguerie C, Bunn CC, Beynon HL, Bernstein RM, Hughes JM, So AK, et al. Polymyositis, pulmonary fibrosis and autoantibodies to aminoacyl-tRNA synthetase enzymes. Q J Med. 1990;77(282):1019-38.

4. Plastiras SC, Soliotis FC, Vlachoyiannopoulos P, Tzelepis GE. Interstitial lung disease in a patient with antisynthetase syndrome and no myositis. Clin Rheumatol 2007;26:108-111.

5. Cottin V, Thivolet-Bejui F, Reynaud-Gaubert $M$ et al. Intersticial lung disease in amyopathic dermatomyositis, dermatomyositis and polymyositis. Eur Respir $\mathrm{J}$ 2003;22:245-250.

6. Späth M, Schröder M, Schlotter-Weigel B, Walter MC, Hautmann H, Leinsinger G et al. The long-term outcome of anti-Jo-1-positive inflammatory myopathies. J Neurol 2004; 251:859-4.

7. Solomon, Joshua; Swigris, Jeffrey J and Brown, Kevin K. Doença pulmonar intersticial relacionada a miosite e a síndrome antissintetase. J. bras. pneumol. [online]. 2011, vol.37, n.1, pp. 100-109. ISSN 1806-3713.

8. Christelle Sordet, Joëlle Goetz, Jean Sibilia. Contribution of autoantibodies to the diagnosis and nosology of inflammatory muscle disease. Joint Bone Spine 2006;73:646-654

9. Koreeda Y, Higashimoto I, Yamamoto M, Takahashi M, Kaji K, Fujimoto M, et al. Clinical and pathological findings of interstitial lung disease patients with anti-aminoacyltRNA synthetase autoantibodies. Intern Med. 2010;49(5):361-9.

10. Tillie-Leblond I, Wislez M, Valeyre D, Crestani B, Rabbat A, Israel-Biet D, et al. Interstitial lung disease and anti- Jo-1 antibodies: difference between acute and gradual onset. Thorax. 2008;63(1):53-9.

11. Katzap E, Barilla-LaBarca ML, Marder G. Antisynthetase syndrome. Curr Rheumatol Rep. 2011 Jun;13(3):175-81

12. Nalotto L, laccarino L, Zen M, Gatto M, Borella E, Domenighetti M, Punzi L, Doria A. Rituximab in refractory idiopathic inflammatory myopathies and antisynthetase syndrome: personal experience and review of the literature. Immunol Res. 2013 Jul;:56(2-3):362-70.

13. J. Behr, J. H. Ryu SO. Pulmonary hypertension in interstitial lung disease. Eur Respir J. 2008;31(6):1357. 